\title{
WHAT IS HOME? THE PERSPECTIVES OF TRAVELING PROFESSIONAL WORKERS IN VIETNAM
}

\author{
MY NGUYEN DIEN TRAN* AND ADAM WEAVER $†$
}

*Department of Tourism, Sport and Society, Lincoln University, Lincoln, Canterbury, New Zealand †School of Hospitality, Tourism and Sport, Niagara College, Niagara-on-the-Lake, Ontario, Canada

\begin{abstract}
Defining home has become a complex matter in a mobile world. With many people now able to move fairly freely and having a number of options with respect to where they can reside, the conventional concept of home that links it to one particular place is no longer as useful. Drawing from a qualitative study of 34 traveling professional workers (TPWs) in Da Nang and Hoi An in Vietnam, the article explores how home is perceived among this group of international migrants. TPWs think of themselves as having more than one home. The article also distinguishes between two related notions: "temporary home" and "permanent home." Key factors that can influence the TPWs' perception of home are identified, including physical exposure to the place, social relationships, a sense of belonging, and employment. Overall, the article explores the concept of home-settling and dwellingamong a group of professional workers employed within the tourism and hospitality industry who are pursuing their careers in a place other than their original home. The concept of home has evolved for migrants who are highly mobile and whose profession offers them opportunities to work internationally; in this context, home is a multifaceted phenomenon. Home has to be considered in relation to relocation as well as being tied, even if temporarily, to a specific place.
\end{abstract}

\section{Key words: Home; Traveling professional workers (TPWs); Mobility; Tourism; Vietnam}

Introduction

The question "what is home?" is sometimes answered with the response "where I was born" or "where my family is." The answer can also be a more complex one. Home can be defined across several spatial registers, such as a house, neighborhood, or nation (Morley, 2000). However, such a view has become less useful due to the complexities of globalization and migration. The concept of home among migrants can be complex due to the mobility involved. The geography of home has been extended to a much wider scale- the globeand therefore the notion of home nowadays is not only influenced by geographic space but also by one's feelings. The question "what is home?" can be answered with reference to what makes one feel at home. Travelers, especially long-term ones, are 
distant from their original home for an extended period; their concept of home is influenced by their time away. They are "on the move" at various points in their careers but they also take up residence in various places.

Different types of movement are associated with different types of home: second homes, online homes, and mobile homes (Hall, 2014; Molz, 2008; Star, 2000). Understanding home is important to individuals as it has been known to be linked to both personal and social identity (Ginsberg, 1999). Tourism development in countries such as Vietnam is supported by the presence of professionals from other places who, in the context of their travels due to work, attach meaning to certain places considered to be home. There is the home that has been left behind as well as the potential for newer, adopted homes to emerge.

Bardhi (2006) argued that there have been limited studies of transnational mobile professionals who represent an emerging group worldwide as a result of the development of the global economy. Some of these professionals play a role in fostering tourism development. By focusing on a particular group of migrants, this article responds to the need for more studies of mobile professionals - in this case, traveling professional workers (TPWs). These workers are travelers who combine work with tourist pursuits, and engage in tourist-oriented activities only as a by-product of their excursion (Uriely, 2001). They represent a growing group of international migrants, some of whom move from developed to developing countries. The perspectives of working professionals with respect to home, especially those working in the tourism and hospitality industry and who are choosing to work in developing countries, deserves attention. In developing countries, encouraging the growth of the tourism and hospitality industry requires international expertise; some understanding of the circumstances of the people who offer this expertise would therefore have merit.

This Vietnam-based research explores an aspect of the TPW journey: the extent to which a particular category of migrant conceptualizes "home." The article aims to advance understanding about the perception of home in a mobile world from the perspective of TPWs. Initially, a literature review regarding the concept of home is provided, together with a closer look at TPWs. The research methods used in this study are then outlined followed by a discussion of the findings. Finally, the article offers conclusions and suggestions for further research with regard to home and mobility.

\section{Literature Review}

\section{Definitions of Home}

Tourism studies have predominantly assumed that home is a fixed place of residence, that there is a home and an away (White \& White, 2007). It exists at different spatial scales, ranging from one's place of residence, an abode, as well as one's country of origin (Morley, 2000). However, the boundary between "home" and "away" has become blurred with increasing global mobility (Ashtar, Shani, \& Uriely, 2017; Huang, King, \& Suntikul, 2017; Shani, 2013; Uriely, 2010). This fuzziness has challenged the current definitions of home and indicated a gap in the literature with regard to understanding the concept of home among people on the move.

Home may also be renegotiated within mobile contexts. The concept of home for mobile individuals surpasses spatial or territorial definitions, and comprises instead an area of social and personal dimensions (Pocock \& McIntosh, 2013). With the notion of a global abode, home should be understood as fluid, mobile, and plural as well as a site of attachment and grounding (Molz, 2008). Such a view acknowledges the emotions associated with perceptions of home. Likewise, Pocock and McIntosh (2013) argue that home is often viewed as value laden and emotionally charged, and may represent the presence or absence of particular feelings rather than a physical space. Therefore, home should be understood as a multidimensional concept. The concept of home functions within a mobile context as well as one where the spatial attributes of a fixed place can assume different meanings.

Meanings of home become reconstructed within a mobile context as individuals take (internalized) "home(s)" with them (McCaig, 1996). Home can be referred to as a collection of practices, objects, rituals, and emotions that make "feeling at home" a transportable form of attachment and belonging. In addition, Ralph and Staeheli (2011) suggested 
that home can be experienced both as a location and as a set of relationships that shape identities and feelings of belonging. Mobile people may recreate their homes by pursuing meaningful activities (Jackson, 1995), performing familiar mundane routines (Nowicka, 2007), or engaging in special relationships (White \& White, 2007), regardless of location or cultural surroundings. As such, the concept of home is related to individuals and their personal circumstances.

Tourism is sometimes thought of as a journey away from home and a search for experiences that do not resemble those found at home (Ryan, 2004). However, forms of mobility such as long-term travel related to the advancement of one's professional career challenges this ordinarily straightforward "home" and "away" dichotomy. Although there is no universal definition of home, attempts have been made to understand the key factors that make a place home. These factors are subsequently discussed.

\section{Calling a Place Home}

The issue of defining home leads to the challenge of identifying what may affect one's perspective with respect to the notion of home. Research has tackled this problem mostly by focusing on residency (the spatial aspect) and the feeling of being at home (the emotional aspect). The way travelers imagine and perform home in relation to mobility is, as Molz (2008) suggested, less about settling or building home in a new place than it is about finding ways of feeling at home wherever they are. They express their sense of being at home in the world by making themselves comfortable in a series of local places and through localized habits. Travelers' efforts to feel at home anywhere continue to revolve around some of the fundamental attributes of home identified by Castles and Davidson (2000): familiarity, security, and community as well as continuity and control. The feeling of security is particularly important and reemphasized by Sampson and Gifford (2010) in their study about the settlement of refugees in Australia. Physical exposure to a place that has been considered in relation to tourism (Prentice, 2004) potentially has relevance to developing a sense of home among migrants (Castles \& Davidson, 2000). Familiarity and previous experiences play a role.
Migrants' construction of home is an ongoing negotiation of transnational and local attachments (Ehrkamp, 2005). According to Philipp and Ho (2010), the home-making process of migrants is associated with their postmigration adjustment and settlement. They suggest that social relationshipsnamely family ties, networks of friends, or other migrants - can further contribute to the establishment of a sense of home in the country that serves as a destination. Moreover, as mentioned above, since the concept of home is related to individual and personal circumstances, the process one undertakes to make a place home is also varied.

Research by Moran-Taylor and Menjivar (2005) that examined the migrant experience shows that a sense of belonging is an important factor to consider when exploring the meanings of home. Psychosocio well-being, life satisfaction, language skills, and cultural familiarity were also emphasized in a study about the settlement of young immigrants in Canada (Doherty \& Taylor, 2007). People and places are connected. Social relationships and a sense of belonging are therefore two concepts that are not easily separated. Based on the factors that may affect one's feeling of home discussed in this section, the extent to which an immigrant feels at home in their host country can move across a spectrum from being a tourist to a permanent resident (Fig. 1).

The continuum assumes that tourists and permanent migrants are sitting at two opposite ends with the sense of home in the new country being more prominent towards the "permanent migrant" end of the scale. This assumption suggests a potential relationship between the sense of home and the status of the migrant, and presents another gap in the literature in understanding such a relationship.

\section{Long-Term Travelers and Home}

For long-term travelers and migrants, home is a complex phenomenon. Home may be visited by migrants who return to their place of origin (Ashtar et al., 2017). Some travel has a strong "homecoming" component to it and may involve visits to familiar places (Morgan, Pritchard, \& Pride, 2002; Pearce, 2012). People have a place of origin—a first home- - but they may also have second homes.

Uriely (2001) developed a typology of travelers based on their work- and tourist-oriented pursuits: 


\section{As a tourist}

Nonexistent in the country visited

\section{As a temporary migrant}

Nonexistent to potentially taking shape

\section{As a permanent migrant}

Potentially taking shape to taking definitive form

Figure 1. Sense of home in a new country: The tourist and migrant.

TPWs, migrant tourism workers, noninstitutionalized working tourists, and working-holiday tourists. TPWs possess some distinctive characteristics compared to other groups of migrants. They are mainly oriented towards work and engage in touristoriented activities only as a by-product of their excursion (Uriely, 2001). Migrant tourism workers, in contrast, travel to work and have fun at the same time; the desire to work is roughly equivalent to efforts to obtain distinctive tourism-oriented experiences. Noninstitutionalized working tourists engage in work while traveling to finance a prolonged trip; working holiday tourists perceive their work engagement as part of their tourist experience.

Other features that distinguish TPWs from other types of tourism-related migrants are a higher level of skill and a strong professional focus (Bianchi, 2000; Uriely, 2001). Furthermore, TPWs often have no intention of obtaining citizenship when first migrating into the host country as their primary purpose for migrating is job related. They intend to leave the host country after a certain time (Krakover \& Karplus, 2002). A term comparable to TPWs that should be mentioned is "expatriates." Barber and Pittaway (2000) defineed an expatriate as "an employee who has spent the majority of his [or her] career working on temporary and/ or semi-permanent assignments in overseas locations” (p. 352). TPWs and expatriates are similar. However, TPW is a more specific term and refers to a particular segment of workers-namely, professionals who have a strong career orientation.

Pocock and McIntosh (2013) examined the concept of home among long-term travelers and found three different types: meaningful homes, blurred homes, and (re)negotiated homes. "Meaningful homes" reflect the importance of establishing a desired way of life. "Blurred homes" reflect participants' silent resistance to social assumptions, norms, and ways of being in the sociocultural environment to which they had returned. "(Re)negotiated homes” reflect the importance to participants of knowing their identities and feeling accepted by themselves and by others. Long-term travelers may include expatriates on assignment, which is a category that overlaps with TPWs. The way they perceive "home" may fall under the categories suggested by Pocock and McIntosh (2013). Nevertheless, although identified more than a decade ago by Uriely (2001), TPWs have not received a lot of attention from researchers. There are also limited attempts to differentiate this groups from others. This article contributes to understanding TPWs by examining their perceived concept of home. TPWs are mobile and yet still have attachments to place. Those working in the tourism and hospitality industry make significant contributions to tourism development in countries such as Vietnam.

\section{Methods}

This article draws on semistructured, in-depth interviews with 34 TPWs in Da Nang and Hoi An in Vietnam. The interviews were conducted during a 6-week period between August and October of 2013. The findings reported are part of a broader study examining the relationship between the intranational travel of TPWs and familiarization with a new home. The data are derived from the responses of the research participants to interview questions designed to determine participants' perceptions regarding the notion of home. Participants were encouraged to share their ideas of home and reflect on what may affect their perception of home while living in Vietnam. Pseudonyms are used to disguise the identities of participants.

A snowball sampling method was used to select the research participants for the study. It started with five participants known to the researcher prior to the fieldwork; others were approached through a snowball sampling method afterwards. The selection of participants for this study was based on 
some key criteria. First, they had to be foreigners who have traveled to Vietnam primarily for work. TPWs, as individuals with a strong career orientation, were seen as research participants who would take their involvement in an academic study seriously and, potentially, enjoy sharing their ideas and feelings about the meaning home. Second, the participants work in the tourism and hospitality industry, either directly or indirectly, and hold managerial or supervisory positions. Approaching participants from an industry familiar to the person conducting the research interviews (the first author) was seen as a means of establishing a common connection between the participants and the interviewer in a manner that would help facilitate rapport. Focusing on professionals as well as those who were contributing to tourism and hospitality development in Vietnam also meant that there were common attributes across the participants in the sample; participants' experiences would be roughly comparable. Third, participants must have been living in Vietnam for at least 6 months. This criterion ensured that participants spent a sufficient amount of time "away" to then contemplate the notion of "home."

The research participants came from diverse backgrounds in terms of gender, age group, nationality, and employment; 28 of the participants were male and 6 were female. This big difference in gender may reflect a gender bias that manifested itself during the "snowball" recruitment of participants. It may also reflect a reality that the dominant gender of TPWs is male. Most of the participants were between 30 and 49 years old. Their lengths of stay in Vietnam ranged from 6 months to 19 years (Table 1).

The research interviews started with questions that inquired about the participants' backgrounds. Questions were asked about the process of becoming familiar with Vietnam as a place of residence and even a home. Other questions explored the notion of home more deeply. What places are considered to be home? How did the participants define the word home? The interviews were recorded and transcribed.

Qualitative content analysis was undertaken in this study (Smith, 2010). Various references to home-perceptions of home and different types of homes-were identified across the interview transcripts. Segments of text from the transcripts were then compared and contrasted in ways that sought to identify relationships. Quotations from the interviews are used as a means to support the insights that emerged through analysis.

\section{Findings}

\section{What Is Home?}

As mentioned in the literature review, home is a broad concept. The notion of home was understood differently among the participants. First and second homes as well as temporary and permanent homes were often mentioned. This section addresses these notions to help understand how TPWs perceive home. Some of the TPWs provided a general definition of home whereas others discussed having two homes: first and second homes. The first home is often associated with one's birthplace and family; the second home relates to the current place of residence:

I always speak of having two homes. So here in Vietnam, my home is with my girlfriend and a house that we rent. You know, wherever we are living, that is our home. But I also always refer to home as where my family is, because most of my family still live around the same area in the US. So I have a home here, and I have a home in the US. (Brian)

I guess home would probably be Melbourne [Australia] where my parents and my sisters are. But certainly Vietnam is my second home. I've been here long enough, this is where my life is. I've had a house here, and a fiancé, and I might be settling in Da Nang for many, many years. (Max)

Everyone has their own first home yet they may also have a second home. From the participants' perspective, the possibility of having a second home appeared to be related to their opportunities to travel. A person may have one first home, or one first home and one second home, or more than two homes depending on his or her travels. Since TPWs travel for purposes tied to work, the notion of the second home is applicable to their circumstances, particularly their employment opportunities and commitment. This concept of a second home among TPWs is different from how second homes are sometimes defined in the tourism literature-that is, as vacation homes or even tourism sites (Hui, 2008). There are different types of second homes, 
Table 1

Profiles of the Research Participants

\begin{tabular}{|c|c|c|c|c|}
\hline Participants & Gender & Age Range & Country of Origin & Job Title \\
\hline Adam & M & $30-39$ & Switzerland & Restaurant Owner \\
\hline Adrian & $\mathrm{M}$ & $30-39$ & Italy & Opening Manager \\
\hline Andy & M & $30-39$ & Holland & Food \& Beverage Director \\
\hline Anna & $\mathrm{F}$ & $20-29$ & Italy & Health \& Spa Therapist \\
\hline Antony & M & $30-39$ & Australia & Deputy Director of Food \& Beverage \\
\hline Aron & $\mathrm{M}$ & $50-59$ & Scotland & English Teacher \\
\hline Austin & M & $30-39$ & Bangladesh & Executive Pastry Chef \\
\hline Brian & M & $30-39$ & US & Executive Chef \\
\hline Charles & $\mathrm{M}$ & $30-39$ & England & Director in Food \& Beverage Import \\
\hline Edward & M & $30-39$ & Sweden & General Manager \\
\hline George & M & $30-39$ & France & Restaurant \& Bar Owner \\
\hline Harry & $\mathrm{M}$ & $50-59$ & Holland & Business Owner \\
\hline Jack & $\mathrm{M}$ & $30-39$ & Australia & Resident Manager \\
\hline Jane & $\mathrm{F}$ & $30-39$ & South Korea & Assistant Director of Sales \& Marketing \\
\hline Jayden & M & $30-39$ & France & Restaurant \& Bar Owner \\
\hline Jimmy & M & $40-49$ & US & General Manager \\
\hline Liam & $\mathrm{M}$ & $30-39$ & France & Restaurant Owner \\
\hline Mark & $\mathrm{M}$ & $30-39$ & India & Business Owner \\
\hline Matthew & $\mathrm{M}$ & $30-39$ & Italy & Food \& Beverage Assistant Manager \\
\hline $\operatorname{Max}$ & $\mathrm{M}$ & $40-49$ & Australia & English Teacher \\
\hline Paig & M & $40-49$ & Australia & Manager of Event Company \\
\hline Peter & M & $30-39$ & New Zealand & Tour Guide \\
\hline Pierre & $\mathrm{M}$ & $30-39$ & Thailand & Director of Sales \& Marketing \\
\hline Rian & M & $50-59$ & US & English Teacher \\
\hline Rory & $\mathrm{M}$ & $40-49$ & Holland & Business Owner \\
\hline Sabrina & $\mathrm{F}$ & $30-39$ & Germany & Tour Company Owner \\
\hline Saffron & $\mathrm{F}$ & $30-39$ & Holland & Health \& Spa Manager \\
\hline Sandra & $\mathrm{F}$ & $40-49$ & England & English Teacher \\
\hline Shawn & M & $20-29$ & India & Wellness Consultant \\
\hline Sonia & $\mathrm{F}$ & $40-49$ & Belgium & Restaurant \& Bar Owner \\
\hline Terry & $\mathrm{M}$ & $40-49$ & Thailand & General Manager \\
\hline Theodore & M & $20-29$ & France & Club Manager \\
\hline Thias & $\mathrm{M}$ & $50-59$ & Holland & General Manager \\
\hline Tom & $\mathrm{M}$ & $40-49$ & Australia & General Manager \\
\hline
\end{tabular}

Source: Reproduced with modification from Tran and Weaver (2016, p. 202).

and this research points to a type oriented around work-related responsibilities.

Moreover, from the perspective of TPWs, the notion of home is perceived within an era of high mobility. As Uriely (2001) indicated, TPWs travel overseas primarily for work and therefore their time in the host country is often based on their work contract. Due to the nature of their jobs, committing to stay in one place forever is not practical. In addition, since they have to move so often to different places, some of them find it hard to identify what home is:

I mean as a hospitality person, you move around a lot. You know, I have a house here; that is where I live. Is it my home in the definition which a lot of people define as a home? I don't think so. I mean we own a house in Australia. Is it our home? No, it is not. We rent it out to other people. So I don't really feel that we have a home in the terms that other people would regard it as a home. You know I grew up in a home, lived 20 years in one house with my family. ... I don't have that feeling ... not just here but anywhere. I mean as part of my job, I move around a lot, so you kinda feeling a little bit temporary, no matter where you are. (Tom)

The research participants sometimes spoke to the issue of mobility and rootedness, and their remarks addressed a complex relationship between the two with which they were coming to terms.

In general, the concept of home among TPWs is subjective. The more opportunities there are to 
travel for work, the more homes they might have. The conventional definition of home is related to family and personal roots. For TPWs, due to the nature of their jobs that requires them to travel, they often perceive themselves as having more than one home. The conventional definition of home can be applied to their perspective with respect to a first home, while their second homes are usually associated with places where they travel for work. According to Rapport and Dawson (1998), home brings together memory and longing, the tangible and the intangible, the emotional and the physical, the spatial and the temporal, the local and the global, the positive and the negative. First homes were often associated with a mix of these various elements; second homes, however, had a narrower, more utilitarian purpose tied to one's career. Degree of permanence was also an issue that arose-and fairly prominently at that — when first and second homes were discussed.

\section{Temporary and Permanent Homes}

The difference between temporary and permanent homes is identified through a number of elements. First, it is based on the amount of time one stays at the place. There is no required length of stay in a certain place to call it a temporary home. For example, according to the research participant named George, the period could be approximately 8 to 9 months, while Shawn thinks that it is about 6 months. For others, "temporary home" is associated with knowing that one will eventually leave. This phenomenon is often caused by the nature of their employment:

Temporary means ... anytime. For expats, we have contracts and that means there is an end day, even though it can be extended. (Jane)

In contrast to a temporary home, a permanent home requires spending a lot more time there:

Permanent is a place where you live and you spend all your life. (Sonia)

The stay at a certain place, for TPWs, is rarely permanent. Temporary work commitments are the main reason for this situation. However, the difference between temporary and permanent homes depends on one's mindset: Interviewer: What do you think is the difference
between a temporary and permanent home?

Peter: The mindset. If you think it is permanent, then it is permanent. If it doesn't feel permanent, then it is not.

Sabrina provided a similar answer to the same question:

I think it is your attitude, whether you have the mindset that says "okay, I am gonna come here and behave like a visitor" or "I am gonna come here and try living like anyone else does."

It is understandable that the concept of home is governed by one's mindset because it is linked to personal feelings. Permanence is an approach to one's circumstances as much as it reflects the presence of a built structure (a house or a home). This finding also confirms that the perception of home is subjective. Similar to mindset, another personal factor that can help to distinguish between a temporary and a permanent home is age:

The difference between temporary and permanent is age. Everything is temporary when you are in your 20s. Then you get into your middle 30s, and ... I don't know, you just feel more in your head, you feel more grounded, not in a good or bad way, you just feel more homely when you get older. (Charles)

Charles's remark shows that personal goals change as one gets older. From the participants' profile, many of the interviewed TPWs are in the age range of 30 to 49 years old. Age may have an impact on TPWs' perceptions of home, and this study did not explore the views of people younger than 30 or older than 49 . The sample of research participants, while narrow in terms of age, did make a distinction between temporary and permanent homes. There was some acknowledgment that a desire for more permanence might increase with age.

Finally, one can identify a place as a temporary or permanent home based on how difficult it is to make a decision to leave the place. The more 
difficult it is to depart, the more likely it is seen as a permanent home:

The difference between a temporary and permanent home is how difficult it is if I have to make a decision to leave. For example, one day when my contract here [Da Nang] is finished, I would try to find a job if I want to stay. But if I can't find a job, then I have no choice but to move to another place. That makes it still temporary. If it becomes a permanent home for me, then that means, even though I can't find a job, I would still stick to the place and try other options to make something happen. (Pierre)

It should be noted that with respect to TPWs, departure from a place might be related to-and is often dependent on - their jobs. Overall, in the case of TPWs, their concept of home is a temporary one rather than a permanent one as they travel frequently.

\section{TPWs'Perceptions of Home}

Factors that influence perceptions of home were drawn from the participants' responses to questions related to the characteristics of a place that contribute to making it feel like home. The factors were divided into four main themes: physical exposure to the place, a sense of belonging, social relationships, and employment. The themes are related to the experiences one has when at or close to home. Each theme is illustrated by a number of remarks from the interviewees.

The first theme includes factors related to the degree of physical exposure to the place. The findings show that familiarity with the place contributes to the participants' perceptions of home:

I am very familiar with the people there. I know my way around so I am very comfortable. (Jack)

Comfort is one of the most important components regarding the feeling of being at home. Being familiar with the place can contribute to help TPWs live more comfortably and thus feel more at home. In addition to the physical surroundings, familiarity with the local people also affects TPWs' perceptions of home:

Home ... you need to feel homely, basically being like ... friendly, comfortable with the people around and the community where you live in. You should not feel like ... you know, out of the community. So yeah, people play the most important part. (Shawn)

Social relationships are the second theme that influences perceptions of home. As TPWs develop more social relationships in the host country, their sense of belonging to the place and their connections to it appear to increase. Examples of social relationships can include friendship, de facto partnerships, and marriage:

Da Nang is my home because, well, it is my wife's home city for one, so . . . my wife's family, my extended family. (Edward)

Social relationships and a sense of belonging are interrelated; people's ties to certain people and certain places are interwoven. The third theme is related to a sense of belonging to the place. Many participants defined a home as a place where their roots are, where they were born, or where their families are. Hence, a sense of belonging seems to be stronger with the first home. It can also develop with a second home. Shawn's previous statement shows that this sense of belonging can be associated with a level of engagement with the local community, similar to Sandra's comment about home:

Somewhere where you feel part of the community. Somewhere where you understand local festivities or customs. (Sandra)

A sense of belonging is also built through the establishment of social relationships within and around the new home.

The themes of physical exposure to a place (Prentice, 2004), social relationships (Philipp \& Ho, 2010), and sense of belonging (Moran-Taylor \& Menjivar, 2005) are mentioned in other works and, as a result, in the literature review. The research participants spoke to these themes repeatedly. A novel theme that emerges from the data regarding the place one calls home, among the other themes already noted, is related to where one's job is situated:

My home is where my job is. (Thias)

A home is a place close to my expectation, for me to be comfortable, where I have my job and, of course, my family. (Jayden) 


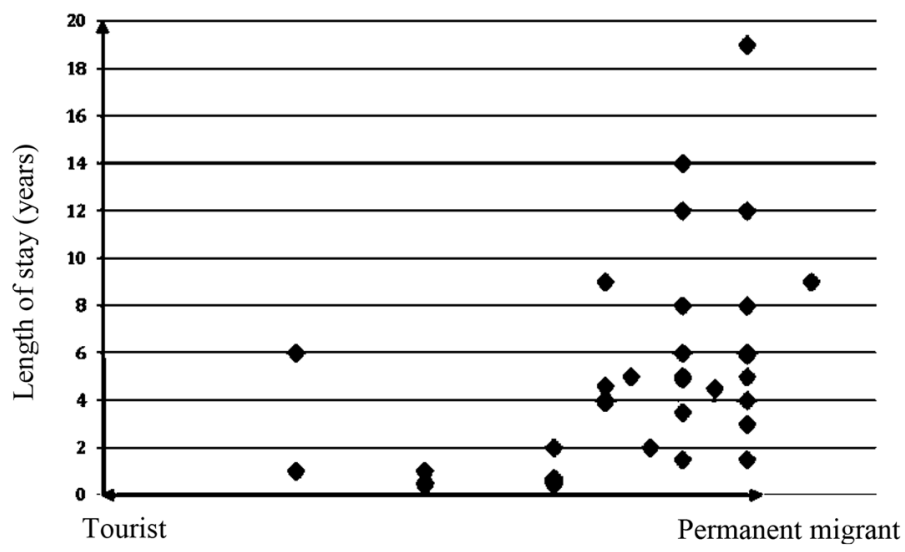

Figure 2. TPWs' self-placement on a tourist-migrant continuum.

As Uriely (2001) indicated, TPWs are very career oriented. Hence, it can be expected that their jobs play an important role in shaping their perceptions of home. This job-centered notion of home is more closely linked to a sense of having a temporary home as opposed to a permanent home. This finding is consistent with an observation made earlier that emphasizes the importance of employment in TPWs' perceptions of home. The connection between an international job opportunity in the tourism and hospitality industry and one's definition of home does seem to have been previously documented.

\section{At Home or on Holiday?}

The intention to make a life (or a home) during the long-term travel experience (meshing work with tourism, routine with novelty, and familiarity with strangeness), and the intention to return to the place of origin (whether it be the nation, community, or a set of relationships) at some stage in the future distinguishes long-term travelers from permanent migrants and traditional types of tourists (Pocock \& McIntosh, 2013). The touristmigrant spectrum was used as a tool to identify the permanence of the TPWs. Do TPWs view Vietnam as a permanent place to settle? The research participants were asked to place themselves on a continuum and provide reasons for their placement (Fig. 2). This exercise took place during the interview. Each dot represents one participant. The graph shows that most of the participants perceived themselves as close to being permanent migrants.
Participants' perceived positions on the continuum do not correspond to their length of stay in Vietnam. For example, though having been in Vietnam for the same period of time, some participants perceived themselves as being more towards the "permanent migrant" end of the continuum than others. No participant considered himself or herself a "full" tourist. This finding is understandable because TPWs have lived, worked, and spent more time in the place. Consequently, they believe they have a stronger connection and know more about the place than typical tourists do. With the assumption that the further one places oneself towards the "permanent migrant" end of the spectrum, the greater the sense of home the person has, Figure 2 suggests a strong sense of home among the TPWs in Vietnam:

I think I am a bit more than a tourist. I live here. I mean ... um ... I can speak a little bit of Vietnamese you know. I am definitely not a tourist. (Tom)

Moreover, the word "tourist" is often associated with mass tourism, which is often perceived as inauthentic and negative (Week, 2012). Research participants were perhaps reluctant to place themselves at the "tourist" end of the continuum for this reason. Some participants saw themselves as "semitourists" or "semimigrants" on the tourist-migrant continuum:

I consider myself $50-50$ because I am familiar with the local area, the local people, the expat community and I feel at home, but in the end, I am still a foreigner. (Mark) 
I still feel somewhere in between because I cannot relate myself to everything here yet. So until I can relate and understand the real Vietnam, and respect for it as well, then I would say I am permanent. (Saffron)

There are several key factors that may influence the participants' perceived status as a temporary or permanent migrant. The first one is the commitment to stay at a place permanently:

Never a tourist but also not a permanent migrant. If I walk around Hoi An and see all these tourists, I would think that I am not like them. Permanent migrants are those who decide to stay here forever. I am not like that. I am here for work and I can move to another place at a certain time. (Thias)

For TPWs whose length of stay at a certain place depends on job conditions, this kind of commitment is a difficult decision. Employment-related circumstances are one reason that some participants hesitate to call themselves permanent migrants.

The second factor is the ability to speak the local language. This issue is mentioned in the literature regarding the settlement process of migrants (Doherty \& Taylor, 2007).

The thing is that my face is white so I would still feel like a tourist at some stage. I am a little bit more than in the middle because I know a bit of the culture. Maybe up further is what I wish, when the local people accept me as a permanent migrant and my Vietnamese is better. (Jayden)

I feel like a permanent resident because tourists don't know much about what's happening here. We [TPWs] know the core of the country, the city or the place we are staying. I'd say $70 \%-80 \%$ [on the continuum], because of course, I have to know the language and a lot of other things to get to 100\%. (Austin)

The findings show that the better the participants can speak the local language, the more they feel like permanent residents. As such, language proficiency can have an influence on helping TPWs become more familiar with the host country and thus perceiving this country as a home.

That participants position themselves differently on the continuum suggest that TPWs include a number of different subgroups. One subgroup includes people who categorize themselves as permanent migrants; a much smaller group sees themselvesasstraddling the "tourist" and "permanent migrant” categories. Several factors may affect TPWs' self-placement on the continuum including the commitment to stay for a long time, local knowledge, and the language barrier. These factors play a role in making people feel at home or feel as though they are tourists - or feel somewhere in between.

\section{Conclusion}

The concept of home evolves as the world becomes more globalized. This article found both similarities and differences in the way TPWs perceive the notion of home. The TPWs in this study seemed to think that they could have multiple homes: first and second, temporary and permanent. TPWs' perception of home is highly associated with their employment commitment. This finding is consistent with their strong career orientation. Research that explores the notion of home among long-term travelers and migrants (Ashtar et al., 2017; Huang et al., 2017; Molz, 2008) has yet to uncover a connection between (professional) work and a sense of home.

By showing the possibfility of making a place home and what matters to those seeking to make a (new) home-either a temporary or permanent one-this article argues that, in a tourism context, "home" and "away" are not necessarily two separate, clear-cut entities. This idea is, very broadly, consistent with the findings of other works (Ashtar et al., 2017; Huang et al., 2017; Shani, 2013; Uriely, 2010). Some TPWs, in this study, developed a sense of (a temporary) home right in their current place of residence- - a place that might be quite geographically distant from their "original” home. This research suggests that the notion of home is complex. Particular groups of migrants-in this case TPWs - may have particular attributes (for instance, a career orientation and a high degree of mobility) that influences their perceptions of home. They realize that work commitments-or the wrapping up of work commitments-require relocation. However, few of the TPWs interviewed see themselves purely as tourists; they are more likely to view themselves as having features one would associate with migrants. TPWs would appear to sometimes occupy a middle ground between lasting 
attachments to and short-term engagement with a place. TPWs have temporary homes as well as permanent homes. The nature of their work means that they have second homes that are clearly subordinate to their first homes but they also see themselves as resembling permanent migrants in the places where they temporarily settle.

The article reemphasizes the complexity of defining home in a world characterized by a great deal of mobility and international opportunities for employment in the tourism and hospitality industry. TPWs can develop a sense of home even within the context of impermanence. A number of factors that can influence a feeling of home are identified: physical exposure to the place (Prentice, 2004), social relationships (Philipp \& Ho, 2010), a sense of belonging (Moran-Taylor \& Menjivar, 2005), and employment. TPWs' perceptions of home are also reflected through their view of their position on the tourist-migrant spectrum. Future research could explore the concepts of home as perceived by different groups of migrants, even different groups of TPWs, and make useful comparisons. The article also touched on a few potential relationships such as sense of home and migration status as well as the impact of age on one's perception of home. Other studies could explore these relationships more deeply or address sense of home in association with other variables or factors.

\section{References}

Ashtar, L., Shani, A., \& Uriely, M. (2017). Blending "home” and "away": Young Israeli migrants as VFR travellers. Tourism Geographies, 19(4), 658-672.

Barber, N., \& Pittaway, L. (2000). Expatriate recruitment in South East Asia: Dilemma or opportunity? International Journal of Contemporary Hospitality Management, 12(6), 352-359.

Bardhi, F. (2006). A life on the road: Experience of geographical mobility and acculturation among transnational mobile professionals. Tourism Analysis, 11(3), 171-180.

Bianchi, R. V. (2000). Migrant tourist-workers: Exploring the "contact zones" of post-industrial tourism. Current Issues in Tourism, 3(2), 107-137.

Castles, S., \& Davidson, A. (2000). Citizenship and migration: Globalization and the politics of belonging. London: MacMillan.

Doherty, A., \& Taylor, T. (2007). Sport and physical recreation in the settlement of immigrant youth. Leisure/ Loisir, 31(1), 27-55.
Ehrkamp, P. (2005). Placing identities: transnational practices and local attachments of Turkish immigrants in Germany. Journal of Ethnic and Migration Studies, 31(2), 345-364.

Ginsberg, R. (1999). Mediations on homelessness and being at home: In the form of a dialogue. In G. J. M. Abbarno (Ed.), The ethics of homelessness (pp. 29-38). Amsterdam, Netherlands: Rodopi.

Hall, C. M. (2014). Second home tourism: An international review. Tourism Review International, 18(3), 115-135.

Huang, W-J., King, B., \& Suntikul, W. (2017). VFR tourism and the tourist gaze: Overseas migrant perceptions of home. International Journal of Tourism Research, 19(4), 421-434.

Hui, A. (2008). Many homes for tourism: Re-considering spatialisation of home and away in tourism mobilities. Tourist Studies, 8(3), 291-311.

Jackson, M. (1995). At home in the world. Durham, NC: Duke University Press.

Krakover, S., \& Karplus, Y. (2002). Potential immigrants: The interface between tourism and immigration in Israel. In A. M. William \& C. M. Hall (Eds.), Tourism and migration: New relationships between production and consumption (pp. 103-118). London, UK: Kluwer Academic Publishers.

McCaig, N. M. (1996). Understanding global nomads. In C. D. Smith (Ed.), Strangers at home: Essays on the effects of living overseas and coming "home" to a strange land (pp. 99-120). New York, NY: Aletheia Publications.

Molz, J. G. (2008). Global abode: Home and mobility in narratives of round-the-world travel. Space and Culture, 11(4), 325-342.

Morgan, N., Pritchard, A., \& Pride, R. (2002). Marketing to the Welsh diaspora: The appeal to hiraeth and homecoming. Journal of Vacation Marketing, 9(1), 69-80.

Moran-Taylor, M., \& Menjivar, C. (2005). Unpacking longings to return: Guatemalans and Salvadorans in Phoenix, Arizona. International Migration, 43(4), 92-121.

Morley, D. (2000). Home territories: Media, mobility and identity. London, UK: Routledge.

Nowicka, M. (2007). Mobile locations: Construction of home in a group of mobile transnational professionals. Global Networks, 7(1), 69-86.

Pearce, P. (2012). The experience of visiting home and familiar places. Annals of Tourism Research, 39(2), 1024-1047.

Philipp, A., \& Ho, E. (2010). Migration, home and belonging: South African migrant women in Hamilton, New Zealand. New Zealand Population Review, 36(1), 81-101.

Pocock, N., \& McIntosh, A. (2013). Long-term travellers return, "home?” Annals of Tourism Research, 42, 402-424.

Prentice, R. (2004). Tourist familiarity and imagery. Annals of Tourism Research, 31(4), 923-945.

Ralph, D., \& Staeheli. L. A. (2011). Home and migration: mobilities, belongings and identities: home and migration. Geography Compass 5(7), 517-530. 
Rapport, N., \& Dawson, A. (1998). Migrants of identity: Perceptions of home in a world of movement. Oxford, UK: Berg.

Ryan, C. (2004). Tourism is the edge: An essay in margins and liminalities. Tourism Recreation Research, 29(3), 61-67.

Sampson, R., \& Gifford, S. M. (2010). Place-making, settlement and well-being: The therapeutic landscapes of recently arrived youth with refugee backgrounds. Health \& Place, 16(1), 116-136.

Shani, A. (2013). The VFR experience: "Home” away from home? Current Issues in Tourism, 16(1), 1-15.

Smith, S. (2010). Practical tourism research. Wallingford, UK: CABI.

Star, S. L. (2000). From Hestia to home page: Feminism and the concept of home in cyberpsace. In D. Bell \&
B. Kennedy (Eds.), The cybercultures reader (pp. 632643). London, UK: Routledge.

Tran, M. N. D., \& Weaver, A. (2016). Intranational travel, traveling professional workers, and familiarization with a new home. Tourism Review International, 20(4), 197-210.

Uriely, N. (2001). "Travelling workers" and "working tourists": Variations across the interaction between work and tourism. International Journal of Tourism Research, 3(1), 1-8.

Uriely, N. (2010). Home and away in VFR tourism. Annals of Tourism Research, 37(3), 854-857.

Week, L. (2012). I am not a tourist: Aims and implications of "travelling.” Tourist Studies, 12(2), 186-203.

White, N. R., \& White, P. B. (2007). Home and away: Tourists in a connected world. Annals of Tourism Research, 34(1), 88-104. 